\title{
Aboriginal health programming under siege, critics charge
}

$\mathrm{T}$

he federal government is deliberately undermining capacity to generate accurate Aboriginal health data and circulating discredited health data so as to downplay the severity of the Aboriginal health crisis in Canada, critics charge.

The strategy includes attempts to undermine national data-gathering capability; publishing data that understates infant mortality and suicide rates; and slashing funds for Aboriginal associations that were involved in datagathering and research, the critics add.

"My fear is that the government is reverting back to generating Aboriginal health policies without input from Aboriginal researchers," says Claudette Dumont Smith, executive director of the Native Women's Association of Canada. "We no longer get to participate in health programs, including many with research components. We've been silenced."

National Aboriginal health data is "shabby," Dr. Michael Kramer, professor of pediatrics, epidemiology and biostatistics at McGill University in Montréal, Quebec, says, adding that the government's decision to abolish the mandatory long form census casts serious doubt on its commitment to generating reliable data on Aboriginal health conditions.

Several others concur. "This appears to be a concerted effort by the government to diminish the collection of data about Aboriginal health conditions," notes Peggy Taillon, president of the Canadian Council on Social Development, a nongovernmental association in Ottawa, Ontario, that has filed a lawsuit against the government for abandoning its responsibility to collect data on Aboriginal and other disadvantaged communities.

"If you don't ask the question you don't get the data. And if you don't have the data you don't have to respond to the health needs," she says, adding that the association is equally disturbed by discontinuation of such initiatives as the Aboriginal Children's Survey.

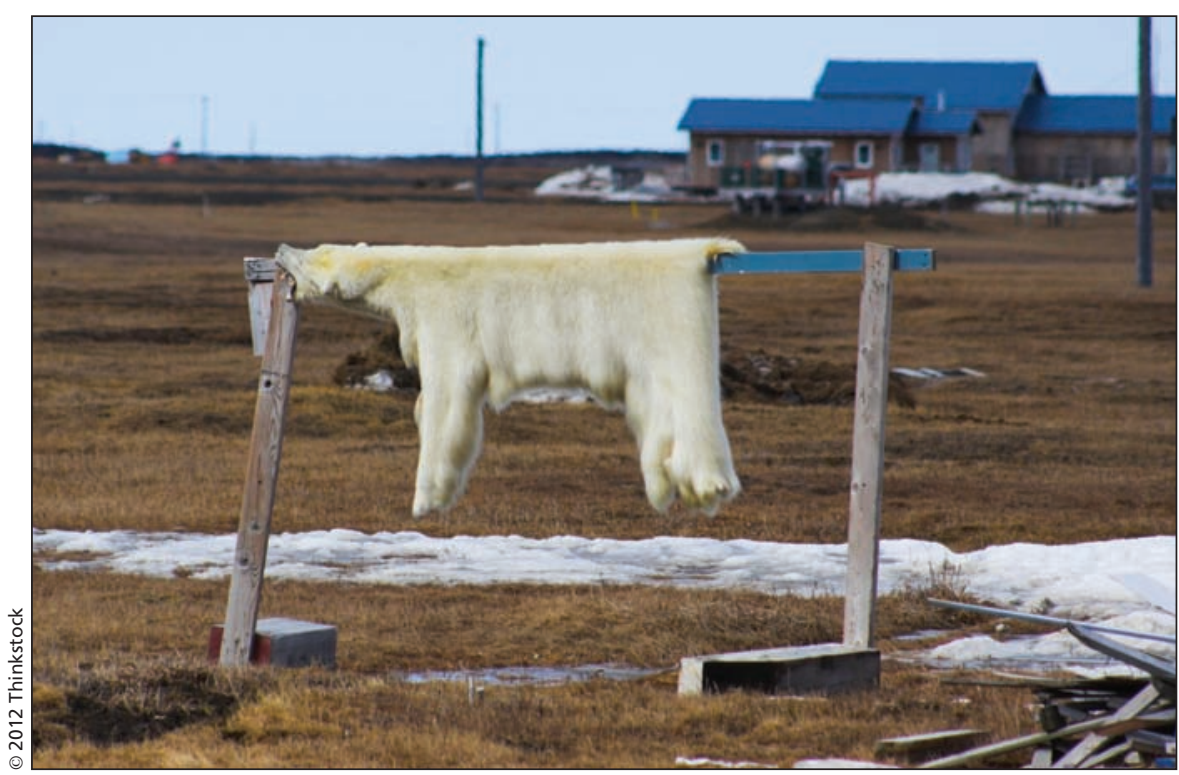

Life expectancy among the Inuit is $\mathbf{1 5}$ years shorter than the Canadian average, while suicide rates are 11 times higher, and infant mortality rates 3 times higher, than the national average, according to Inuit Tapiriit Kanatami.

Among the most egregious elements of the campaign is the publication of inaccurate infant mortality data, charges Dr. Janet Smylie, associate professor of family medicine at the University of Toronto in Ontario and research scientist at the Keenan Research Centre of the Li Ka Shing Knowledge Institute of St. Michael's Hospital.

Public Health Agency of Canada (PHAC) data asserts that the infant mortality rate on Aboriginal reserves is 7 deaths per 1000 live births, about $40 \%$ higher than the national average (www.phac-aspc.gc.ca/cphorsphc-resp cacsp/2008/fr-rc/cphorsphc-respcacsp 06c-eng.php).

But Smylie's studies, conducted under the rubric of the Canadian Perinatal Surveillance System, indicate that the rate is at least double the national average (Can J Public Health 2010; 101:143-48). "The government continues to dodge the facts on Aboriginal infant mortality," she says.

The cuts to Aboriginal research capacity, meanwhile, pose a long-term threat to evidence-based Aboriginal health care, warns Dr. Marcia Anderson
DeCoteau, assistant professor of community health sciences at the University of Manitoba in Winnipeg and past president of the Indigenous Physicians Association of Canada. "What gets measured gets done."

Smylie's evidence that Aboriginal infant mortality rates are incorrect is likely typical of other indicators of Aboriginal health status that are either misreported or unknown, DeCoteau adds. "Life expectancy among Aboriginal people is also a contested core indicator. I believe the official figures underestimate inequities in life expectancy by at least 30\%."

At least 10 Aboriginal bodies have had their health research funding recently cut by the government, including the Native Healing Foundation, the National Aboriginal Health Organization, the First Nations Statistical Institute, the Native Women's Association of Canada, the Métis National Council and Inuit Tapiriit Kanatami.

"We're seeing a systematic rollback in Aboriginal health research capacity," says Bruce Dumont, president of the Métis Nation of British Columbia, and 
Minister of Health for the Métis National Council. "These cuts could well be terminal for Métis-led health research, which was in its infancy."

Similarly, Terry Audla, president of Inuit Tapiriit Kanatami, argues that the cuts impair the ability to "meaningfully engage" in health research at a time when life expectancy among the Inuit is 15 years shorter than the Canadian average, while suicide rates are 11 times higher, and infant mortality rates 3 times higher, than the national average.

The money the government saved through such cuts "will be lost many-fold as the flow of information and the creation of new knowledge and capacity with which Aboriginal peoples were addressing their health inequities ceases," argues Sylvia Abonyi, Canada Research Chair in Aboriginal Health at the University of Saskatchewan.

Health Canada has also slashed intramural funding for a host of Aboriginal programs, including ones to address diabetes, fetal alcohol syndrome, youth suicide, infectious diseases and maternal and child health. The cuts prompted Thomas Dignan, chair of the Royal College of Physicians and Surgeon's Aboriginal Health
Advisory Committee and acting community medicine specialist for Health Canada's First Nations and Inuit Health Branch in Thunder Bay, Ontario, to decry that "the state of Aboriginal health is a national embarrassment and leadership is needed now more than ever" (www.royalcollege.ca/portal/page /portal/rc/news/Newsroom/NAHO's\%20 loss $\% 20$ is $\% 20 \mathrm{a} \% 20$ blow $\% 20$ to $\% 20 \mathrm{Ab}$ original $\% 20$ health?_template $=/ \mathrm{rc} / \mathrm{item}$ _tpl_pblc_news).

For its part, the federal government says it is now examining the accuracy of infant mortality data and is shifting Aboriginal health research funding under the rubric of the Canadian Institutes of Health Research (CIHR), according to PHAC spokeswoman Sylwia Gomes and Health Canada spokesman Gary Holub.

Gomes says the agency is aware that the figures it publishes on Aboriginal infant mortality have been challenged and notes that Health Canada's First Nations and Inuit Health Branch "is currently addressing the quality of First Nations and Inuit infant mortality data through regional engagement with provinces, territories, and Aboriginal peoples."
Holub explains that as part of a government-wide administrative overhaul, federal Aboriginal health research funds "will primarily be administered through the Canadian Institutes of Health Research, while Health Canada focuses primarily on overseeing the First Nations and Inuit Health program."

CIHR has invested \$151.5 million in health research related to Aboriginal peoples' health since 2006, including $\$ 31$ million in fiscal 2010/11, Holub notes. He adds that CIHR launched a \$25-million initiative aimed at understanding how to reduce Aboriginal health inequities.

But Malcolm King, scientific director for the CIHR's Institute of Aboriginal People's Health, believes that many of the Aboriginal health organizations that have been defunded by Health Canada played an important role in helping CIHR-supported researchers establish community-based research programs. The cuts "certainly make it more difficult for Aboriginal organizations to participate in health research," he notes. - Paul Christopher Webster, Toronto, Ont.

CMAJ 2012. DOI:10.1503/cmaj.109-4282 